\title{
“These Girls, We Should Not Allow Them Do PhD": Perceived Realities and Reactions of Some Never-married "Akada” Ladies
}

\section{Olayinka Modupe Onayemi}

\author{
Department of Sociology, \\ Landmark University, Nigeria
}

Doi: 10.36941/jesr-2020-0027

\begin{abstract}
Crossing the culturally perceived appropriate marriage age, especially for single ladies is deviant in some societies, so also is advanced academic ("Akada") pursuit for women. The experience of falling within both categories might be confounding, yet, have not received much research attention. This study explored how, this social 'comorbidity' informs social relations of this category. The study adopted phenomenological approach. Qualitative semi-structured interviews were held with 20 never-married ladies who were either undergoing or have obtained their Ph.D. The involuntarily never-married "akada" ladies reported the popular opinion that too much academic degrees keep men on the run as a major concern. They also shared basic coping strategies and perceived benefit of their dual status. While some never-married "akada" women fail to notice this socially conceived ills in order to advance, the ill-opinions was reported to debar many nevermarried ladies from taking conscious effort towards getting additional degree for their improvement. Finally, the study reveals that the popular negative opinion about the "Akada" ladies somewhat further reinforces their singlehood, and better explains their protracted singlehood than the rhetoric of never-married "akada" ladies being too busy. Hence, the need for a re-orientation.
\end{abstract}

Keywords: Women education; advanced academic degree; Social perception; Never-married; Coping strategy

\section{Introduction}

Single life could be satisfying and meaningful as captured in the narratives of some single women (Baumbusch, 2004), however, studies (Fong \& Amatea, 1992; Situmorrang, 2007; Tan, 2010; Himawan, 2017) have shown that singles reportedly have significantly higher level of stress symptoms than the married. Such level of stress, may not be unconnected to pressure that this category face within and without, more so that unmarried persons receive blame for their status as it is mostly attributed to characterological flaws (Byrne \& Carr, 2005). In some cases, prolong singlehood have been attributed to seeking opportunity for a higher educational level and generally, the need to enhance their development (Lewis \& Moon, 1997).

Earlier studies (Becker, 1981; Sweeney, 2002) have argued that the advanced growth of economic activities stimulate, among other things, greater financial independence, and increased personal efficacy which likely lower the sense of having the need for a helpmate. Ntoimo (2012) and Bryne and Carr, (2005) among others have documented the lived experiences of prolonged singles, and of the challenges of female participation in academic career pursuit. Culture, especially, in the developing societies continues to play significantly in women's educational deprivation (Latif, 2009: Robinson- 
pant, 2004; Khan\& Ali, 2005), as well as acting to discourage individual and concerted efforts towards female career progression. For instance, the notion that, in marriage, a lady is given out to another family discourages some parents from making full commitment towards their female child's educational advancement (Haq, 2000).

Oyeronke (2011) notes the male dominance in scholarship, in terms of gender composition, however, was more concerned with refuting the popular explanation of this dominance as the traditional way of ordering life within the Yoruba culture of South-western Nigeria. In Yoruba religious culture, Ifa, is the deity of Knowledge (Akinwowo, 1990). The attribution of the gendered male to the Supreme Being - Ifa, according to Oyeronke lacks evidence in oral tradition, however, such attributions hold sway to denote such epitome of knowledge as a gendered male. Kamau (2011) submits that in Kenya, the original intention of western education was towards male empowerment, however, in the event of its reach to the females, it came with a call for the women to receive it with all sense of adaptability. In other words, women, were called to preserve the African culture, and internalise the patriarchal idea of women domesticity and the place of women in the cultural space. Onsongo (2004)'s study on factors affecting women's participation in university management revealed the role played by women's poor self-perception which is rooted in the popular belief that women's roles are domestic, and that women who succeed in the public domains are sure failures in domestic matters. Though there is a mass enrolment of the girl child in western education in recent times (Mawusi \& Manieson, 2015), partly due to persistent advocacy to this effect, women are still not wellrepresented, especially in the top cadres (Labourne, 1996). Advanced educational pursuit by ladies still creates a cultural dilemma as a result of the cultural construction of some heights of career as manly. Generally, a kind of dilemma arises when a gender crosses to area perceived as non-traditional (Still, 1994), in fact, Robertson (1985) unambiguously noted that a new dilemma is created for an African women when she possesses western formal education. This continues to present a wide gendered ratio between occupation entry and representation at the top positions (Zubaidah, Penafort, Jusoff, \& Marzuki, 2008), resulting in women being poorly represented at the realms where their fate is decided.

While a number of studies (Asare, 1997; Quartey, 2003; Hallman \& Grant, 2004; Lee \& Meyers, 2005; Mawusi, \& Manieson, 2015) have documented various unique challenges that married women in school face, there is a dearth of study on the experiences, perceived realities and reactions of nevermarried, certificates-accruing women. This category are most likely to have experiences that differ qualitatively from other single women who are widowed, divorced, separated, or are even nevermarried with low educational profile. The dual identity of this category, in a patriarchal society, as prolonged singles and career ladies may be implicating them in a "double-tragedy". This predictions necessitated exploring issues that border on the social relations of this category, focusing on the perceived realities and reactions of this category. This study therefore attempted bridging the gaps in knowledge by exploring the subjective experience of the co-existence of prolonged singlehood and high academic pursuit of some women. Specifically, it explored how this social 'comorbidity' informed social relations within their immediate environments, the reactions to it, as well as its consequences on this category of people.

\section{Materials and Methods}

The study adopted a phenomenological approach and the research design was exploratory. This allow for an in-depth understanding of the participants' subjective experience. Qualitative interview was held with 20 ladies, some of whom were pursuing Ph.D and others had obtained their Ph.D at the time of the interview. Purposive sampling technique was adopted to frame identified ladies above 30 years who satisfied the research inclusion criteria.

Data were collected through a face-to-face semi-structured in-depth interview. The interview guide was designed to focus on social relation concerns. Each session of the interview lasted an average of 36 minutes. The researcher met with individual respondents to explain the focus of the 
research some days earlier before meeting with them at their most convenient times and places. During the data gathering, and after each session, summary of individual submissions were made and confirmed from the individual participants in order to ensure that their ideas were appropriately captured, vagueness and ambiguity were avoided, no important idea was lost and there was no room for assumption. Respondents were informed at the start of the interview about their rights to disengage from the interview or to shy away from any question, where necessary. Participation was voluntary. Consents were granted to audio-record the interviews.

Age-based eligibility was pegged at 30 years. From observation, in the study area, a lady is considered ripe for marriage from her early 2os, while ladies in their late twenties are considered overdue. Hence, participants were either 30 year old or above, majority of whom were on full-time programme, with only one of the ten having a stable job at the time of the interview. Also, none of the participants was married or in any romantic relationship purposed for marriage at the time of the interview. Participants were drawn from a Nigerian university that is reputed for postgraduate studies. Nigeria has three main ethnic groups; Yoruba, Igbo, Hausa. However, only two of these groups were represented as it may be difficult to have a lady from the third ethnic group, who would satisfy the criteria for selection.

In generating the themes and subthemes, individual transcript was analysed concurrently with other participants' and common ideas were grouped together. Also, intra-textual coding was conducted. The researcher, as well as the assistants read transcripts over and over to assimilate the true content and meaning-in-context of participants' submissions. This inter-textual coding allowed for generating broad annotations, under which relevant themes were input, this was then repeated again by the researcher, in order to check that ideas were rightly placed within appropriate annotations.

\section{Results}

Notable themes emerged summarise the narratives of the never-married "akada" ladies under the ill popular opinions of their dual status, relating with the realities, perceived benefits of being nevermarried "akada" ladies, and lastly, wishes and regrets of the never-married "akada" ladies.

\subsection{The concerns of the popular opinion: too much academic degrees keep men on the run}

Many of research respondents had concerns about the popular opinion that women with high academic profile are usually not the desires of most men, hence men run away from them. Such attitudes of men, they stated, ostensibly derive from the popular opinion that such ladies are generally intractable and never submissive.

This opinion and the accompanying attitudes to these never-married eligible "Akada" ladies were believed as not displayed only by men with little or no formal education, but also by a number of the ladies' well-read colleagues. A respondent noted: “...Not necessarily uneducated. In fact the bulk of them are educated. Those who are educated have the complex most, from my observation, they would feel like, "Oh, I have PhD and my wife would have too". Hence, the ladies generally made a clear distinction between qualification or educational certification and maturity or exposure. A participant submitted: “...It depends on mentality, this is not about education now; somebody might be educated but yet immature, and not exposed". Buttressing on this, experiences of some of these ladies revealed that men's affinity to the tradition that subjugate women and sees them as subservient of the male folks has no regard, in most cases for their level of education.

Many of the never-married "akada" ladies showed unreserved concern for the strong hold of patriarchy that bear strong influence on the way that even their well-read colleagues relate to them. They expected that a man who has been exposed to a high degree of education should have unlearnt so many things, but unfortunately, as a particular respondent observed, "religion, culture and personal opinions are strongholds on human and it takes conscious efforts to unlearn and let go of 
opinions that people have built up due to their backgrounds, interactions, and experiences over time". As their PhD colleagues also disappointingly hold such "ill" opinion about them, all of the respondents agree that in this matter, educational status has little or nothing to do with people's mind-set and that educational status may not necessarily change a man's opinion, unless he is determined to let go of some things which he has learnt overtime:

There was a time I had the privilege to eave drop into the conversations of some of my colleagues who sat down at a round-table discussion, I was so embarrassed. Imagine, they were discussing about ladies undergoing PhD with them. They concluded that it is not wise doing a PhD programme as a lady and that they would not even advise any man to go for such a lady, asking for her hand in marriage... that whatever they have, the lady has it and so there would be no difference as men... It makes them insecure. I was highly embarrassed that such men would go such length to pull down ladies who have gone to such heights.

Speaking further on this, a respondent submitted a serious bother on the disjunction between academic qualification and liberality it supposedly conveys. She submits:

It bothers me, not necessarily personally. I am surprised that people that are educated, that I should have felt would be broad-minded... they are the ones still propounding the traditional beliefs that are working against women today. What then is the essence of education? Then it means that education has not made significant impact in the way women are being treated or perceived in the society.

Respondents attributed this general ill opinion and reaction of most men to the men's failure to embrace the liberating effect of education. This antipathy against women's advance education, the ladies claimed, is responsible for the poor interpretation of any act displayed by ladies who are welleducated. Some ladies could not find a direct connection between display of arrogance or pride and ladies' pursuit of higher academic degree. A number described such arrogance as somewhat more psychological than a social trait that may be acquired with improved social status. A respondent posits:

From my little observation, whoever displays arrogance, the trait has been inherent in her. The acquired higher degree was just a platform that she needed to exhibit such traits. If we must be fair to one another, if you go outside there to sample women's character, pride, arrogance, lack of courtesy are common. If we must be fair, these things are not linked to educational background or status. It is normal that whoever wants to explain why you do what you do always look for something around you to point at and you know that that such height of educational attainment is something to be proud of, so they link your actions to it...

To most of the respondents, whether a woman is well-read or not should never define her as "good" or "bad". To them, both sides of the coin have their merits or demerits which must be wellmanaged to have an impeccable home; "Whether you are exposed or not, whatever has advantages comes with disadvantages; there are also inherent dangers in being naive."

All the ladies agreed that education has a liberating effect, hence, educating a woman is tantamount to liberating her. They admitted that an educated lady is equally a necessarily exposed lady as education generally produces effect in liberating and offering its bearers requisite knowledge of her/his rights and duties. Meanwhile, men by nature, the ladies claimed, are egoistic and enjoy cultural backings to be domineering. Some of the participants noted that such nature of men usually leave them apprehensive of ladies who by the virtue of their academic exposure resist any observed infringement on their rights. Such reaction which in fact is culturally strange and lacking social acceptability is usually interpreted to be pride. A respondent reported:

In my own culture, they would tell you that women that go to school are flirt, they are seen as prostitutes because they believe that education would lead to enlightenment, and as a result of that you want to know a lot of things; you would not be submissive to your husband, you would be heady. So, they 
associate women education with being heady and not being submissive and stuffs like that....They attach education to being heady because they believe that once you are knowledgeable it comes with ego, you would be able to challenge them once they are doing something that is wrong.... but they would want you to massage their ego.

From the ladies' perspective, men summarily equate enlightenment to waywardness. Although it was explicitly stated that this reaction is not the case with all men. One of the respondents also reiterates, "Generally, most men in our society have a feeling that the well-educated women become heady, proud, untameable, unamendable and find it very difficult to submit to men". However, ladies who dwelt on this issue rather see this as men's attempt to discourage women's empowerment. They submitted that, some men who pursue higher degree saw it as the reserve of the male folks and that advanced educational degree infuses some sort of "weird" confidence in female folk, but when the women are deprived of it, it would favour the men in maintaining "power" over their women:

We were in a gathering one day where I asked a guy a question he found challenging and the next thing he said was, "These girls, we should not allow them do PhD, look at the question she is asking us" they now think we are the same because they are doing PhD like us. So, even among our colleagues, from experiences, some would not be willing to marry a PhD holder like them because they think a woman with a PhD is proud, difficult to control and can talk to them anyhow.

In the same vein, some respondents mentioned that the pursuit of such higher degree by default makes you necessarily analytical and sometimes requires being pragmatic and these qualities culturally describe you as unwomanly and insubordinate to the male folk who are culturally placed above the women:

PhD has the nature of making you challenge the status quo, and keeps your mind alert. PhD is philosophical; you become Doctor of philosophy and as a philosopher you don't take just anything; you are a deep thinker, you analyse situations and become analytical in your thinking; you don't just respond to situations, there must be a reason for your response. It takes conscious efforts to be able to separate your career from your marriage.

Recalling an event, another respondent narrates a story:

Education is power, once you are educated you know the right thing to do, you know your right. I called for the arrest of a man who was always beating his wife, afterwards, people were amazed at my action and summed it in me being educated and that nobody in that locality can marry me for that action I took; they imagined that was my husband. Such action is what being educated can deliver to you. Once you are educated, you mind is blown. A lot of uneducated women would not react to that, they would be wondering where they would start from should their husbands divorced them. An enlightened woman knows her rights, and that is what the men fear the most. The fact that a woman does not know or even when she knows would not act on it is what they are safe with.

\subsection{Relating with the Reality}

This section is concerned with how never-married ladies view and relate to their statuses and the social realities that accompany the status. It deals with their motivation for proceeding for such height of academic degree despite the somewhat discouraging cultural milieu. It also examined the perceived relative benefits, their wishes/regrets.

\subsubsection{Relating with the dual status: being never-married "Akada" lady}

Regardless of the social prejudices towards prolonged singlehood in Nigeria, and much more, its combined social cost to women acquiring fleet of academic degrees in patriarchal societies, a number of eligible ladies are still acquiring more degrees. This unexpected response to the ill perception may 
be connected to the never-married "Akada" ladies' conception of their statuses.

Majority of the respondents did not see going for a $\mathrm{PhD}$ programme as an issue. They saw it as only a necessity for their career progression. Nevertheless, all of the respondents held a positive outlook and value for marriage: a respondent remarked: " $\mathrm{PhD}$ is something I had always wanted; it is not like an afterthought. I did not really feel I had to wait for marriage, I came into it believing that marriage could always come. In the same vein, another respondent posits:

Yes, I expected to get married before starting my PhD but when it did not happen, I did not have to wait and keep that aspect of my life on hold; I had to continue with my PhD... It was not even an issue to me, until somebody asked me, "are you back for PhD? And I said, "Yes", then she yelled at me:" You should go and get married first!

While some were determined to disregard the ill opinion from the outset, some others, as they continued on the programme, began to hold less concern and to build confidence in themselves and in the path chosen regardless of the popular opinion about them. A respondent stated:

Before now, I would have advised that someone gets married or at least, get into a relationship before starting the programme because of the idea of "guys running away from ladies who hold so many academic degree...No, not anymore...the world is changing, we are getting more knowledgeable about some things; that women could become 'something' without being married.

By way of lessening their concern, and to generally relate with this perceived ill opinion, many of the ladies define their lives around what they think best for them at that time without regard for the negative popular opinion. They also hold their own interpretations to the idea and those who favour it by concluding that any man who runs away for this reason may not be the best for their kind in the first place:

...If the phase of my life at this point is that I am about to get an academic qualification-PhD, it means that it should also help me to be able to sift the wheat from the shaft. I believe the degree is actually going to help you sift men that are not even worth...eehm"...

\subsubsection{The perceived relative benefits of being a never-married yet acquiring higher degrees}

Participants notably conceived their statuses as not without some advantages in that it produces benefits that differentiate them from their fellow eligible single by adding value while waiting for a suitable partner. According to them, it also provides room, within some milieu, for concealing their status as never-married.

\subsubsection{Value-adding: waiting but not wasting}

The never-married "Akada" ladies made it clear that proceeding to acquire the degree was not really informed by their statuses as singles and perhaps, a jobless who just needed to be fixed. Almost all the ladies interviewed mentioned that forging ahead to obtain more degrees is rather an opportunity to add value to themselves while waiting for the "Mr. Right". More importantly, some respondents saw this as a wise choice made as against some of their counterparts who equally desired to proceed but considered acquiring more degrees as an eligible lady, another strike against their marital prospect:

At times I feel late but I console myself that at least all the while that I waited, I added value to myself because I think about those who never added value to themselves thinking that 'Mr right' would run, yet I came meeting them at the same spot, 'Mr right' never came and they never added values to themselves...I took the bull by the horn, forged ahead to add value while I am still waiting for that man. 
A respondent equally notes:

The funny thing about this marriage thing is that, if I did not go for the PhD, I may still not have been married. I would have wasted like two year, not getting married, not doing PhD, and your life is just wasting.

\subsubsection{Status concealment}

Some viewed the programme as marital status-concealing particularly within some formal environment: "It has social benefits, nobody addresses me anyhow. I have my $\mathrm{PhD}$, so I am 'Dr', with that, no one knows whether I am married or not yet married".

This was also reiterated by a respondent who hails from a tribe where the need to accord respect is discriminated by some cultural indices of maturity such as age, marital status and so on, in which the tone of respect is sometimes reflective in the way someone is addressed: "at least if I'm not yet married, when I obtain the $\mathrm{PhD}$, nobody would call me by my name, you know..., it could be insulting...., they would call me "Doctor".

\subsubsection{Wishes/regrets of the never-married "Akada" Ladies}

None of the never-married "Akada" ladies explicitly reported any regret, some only wished they had the chance of being married and yet running the programme. Some however recorded that if the choice was theirs to make, they would have chosen being married above running a PhD. Participant A noted: “...But I am not regretting my decision, it's just that, maybe if I was to choose, I would choose getting married and having kids. Such thoughts come sometimes".

Some of the ladies opined that it is better for a lady to get married or at least be in a relationship before ever taking up such high educational pursuit as $\mathrm{PhD}$ :

I would not say that I would have preferred that because I have colleagues who are married and doing PhD; they are balanced. ...Well, if I was to choose between the two continuums, I would have chosen getting married and having children without doing $P h D$, and later in life after stabilising, I could them pick the PhD. I actually dream to be like them but I don't regret where I am.

A significant number of never-married ladies reported pursuing this advanced degree regardless of the ill opinion about their dual status, after they conceived it as necessary for the selfdevelopment. However, in some of their later submissions, almost all of them still feel it could have been better to be married despite their resolute to obtain this degree. Some of them explicitly would have preferred to be married and later opt for their PhD degrees. This suggests among other things that, to this category, achievement in the academic domain does not still cover up for the marriage front. Hence, their interpretations of self-actualisation still has cultural undertones. In other words, many of the never-married "akada" ladies may have consciously liberated themselves from the popular opinion that is capable of limiting them but are however, consciously or subconsciously defer to that aspect of culture that sees marriage as fundamental index of achievement. This also suggests that most never married "akada" ladies were not voluntarily unmarried or hold aversion to the culture and values of marriage as against the popular opinion that "Akada" ladies barely have time for marriage or domestic matters.

\subsubsection{Turning the back on reality: People and Places Avoided by the Never-married "Akada" ladies}

The never married "Akada" ladies identified that they restrict their interactions within religious settings. Respondents made diverse submissions such as: 
church and go out without much interaction with the people...; in my place of worship, almost every day, they keep on reminding you that you are not married.

Another respondent, explained further:

Even the religious setting, some people look at you as a woman who is not ready for marriage yet, all because you have a Ph.D. Don't be surprised that even in the religious settings, some go behind to 'brothers' and tilt them towards the younger ladies.

Some never-married "Akada" ladies also avoid their old friends especially those who are married but not as educated as they are. Participant A stated as part of the reasons, the non-compatibility of values, goals and interest, in most cases, a situation that naturally sets them apart:

...I avoid my secondary school association, basically because I am not married. That kind of setting, having kids, having husbands is their priority, and with those, it is to them that they have "arrived". Meanwhile you are perceived as ordinary person; your PhD does not matter to them.

\section{Discussion of Findings}

The never-married "Akada" ladies found no connection between women's education and insubordination but rather admitted that such advance educational pursuit only necessarily make one highly pragmatic and analytical and has a liberating effect in a way that furnishes its bearer with requisite knowledge of his/her rights as well as empowers them to maximise same. This is consistent with the views that education is an indispensable tool in empowering women, and dealing with oppressive customs and traditions that oppose women's wellness (Arab, Umar, Waseem, Mohammad, Qausar, 2011; Jebeebboy 1998). According to the scholars, women's education reduces violence against them. The UNDP (1998) equally recognises that a rise in women's level of education results to increased consciousness of their rights, leading to positive changes in their lives (Arab, Umar, Waseem. Mohammad, Qausar, 2011). The respondents submitted that these are the attributes most men naturally guide against in order to maintain their power over the women. Hence, where the possibilities of maintaining such unfettered power appear slim, such women are labelled as "unsuitable" and unwomanly.

The observed antipathy demonstrated by men towards women's advanced education likely spoons prejudices and intolerance, resulting into summary opinion on the "akada" ladies not being considered as marriageable. This supports Baumbusch's (2004) study of single women who though confessed to living satisfying and meaningful lives still suffer social stigma and prejudices that surprisingly exist even in this modern societies. The finding may also reveal the limitedness of the argument that is put forward by earlier study (Furstetenberg, 2015) on how the high expectation of professional ladies or the notion that that this category has less time or opportunity to interact (Yoshida, 2017) are responsible for the difficulty in getting men who meet their requirements. The negative popular opinion about the "Akada" ladies somewhat further reinforces their singlehood, and better explains their protracted singlehood than the rhetoric of never-married "akada" ladies being too busy.

As either a coping or retreating strategy, the never-married "akada" ladies avoided some persons and places where less value is placed on academic achievement. They avoid people who overstretch marriage values to the point of negative stereotyping. This strategy is quite different from some who deal with the pressure by creating a counter argument to the values and beliefs around marriage (De Paulo, 2013). The notion posited in earlier studies (Dingermans \&Ingen, 2015: Mana, Sagy, and Srour, 2016) that singles are likely to enjoy the religious company of others considering that religious environments discourages stigmatisation, through the provision of a sense of acceptance and identity lacks support in this study. 


\section{Conclusion}

Generally, all these resonate with the idea that, "the society do a great disservice to the female by raising the girls to cater for the fragile ego of men, by teaching girls to shrink themselves and in a way, the society tells girls they could have ambitions but not too much, we tell them to aim to be successful but not too successful otherwise they would threaten men". The never-married "Akada" ladies who were brave to pursue such height of academic degree may share some characteristics: they consider themselves as better off some of their counterparts who have been shrunk by societal opinion, and discouraged from taking such steps, yet kept waiting for men to marry them. It therefore suggests that most never-married "akada" ladies at the point of making the decision to forge ahead, disregard this limiting culture whose socialisation of her female is focused on men. In order to overcome these concerns, though the society may never be able to deny the stronghold and reality of culture, she (the society) must instead embrace a pro-women advancement culture, a culture that would define women as same in intellectual abilities, with no inherent difference from their male counterparts. This is instructive, based on the reported contribution of women to micro and macro levels of development.

\subsection{Practical implications}

Never-married ladies who have crossed a culturally-perceived appropriate age for marriage may hold reservations for academic progression or educational advancement. This is in consideration of the illopinion on prolonged singlehood as well as the reported reaction of men to never-married ladies who in addition, pursue advanced educational degree. In effect, this discouragement may translate into a fall in the enrolment of women, especially the never-married, for advanced personal development, hence, their poor representation in high academic positions. Although the never-married women who may be discouraged in taking up such advanced academic degree constitute a small fraction of women population, they are still a significant part. Evidence shows that the development and liberation of any society politically, economically, and socially is rooted in building a sound base of educated women (Haq, 200o).

\subsection{Social policy implications}

The reported experiences of the never-married "akada" ladies, projects that of subjugation and repression, and as those occupying a second place, even in this modern society. The experience, which were uniformly reported as displayed by their well-read male colleagues suggests the need to adopt a different form of education. As reported by the never-married, the repression is a product of men's affinity to suppressive traditional culture that aims at keeping the women perpetually under male dominance. Public orientation may be an important tool in ending women's discrimination and its attendant ill-consequences. However, this education must target dispelling myths and cultural ideologies that relegate women, in order to reposition them as having equal place within the society. Across all levels of education, this may be consciously or symbolically presented in arts and culture until such myths totally fade away. Also, in deploying these myths, a catch-them-young approach may be suitable, in which the focus would be on the young. 


\section{References}

Akiwowo, Akinsola. (1990). Contributions to the sociology of knowledge from an African oral poetry. In Globalization, Knowledge and Society: Readings from International Sociology eds. Martin Albrow and Elizabeth Kind. London: Sage Publications/International Sociology Association.

Arab, N. Umar, D. Waseem, K. Mohammad, H. Qausar, K. (2011). The dormancy of empowerment: An analytical study of various impediments to women's education in Khyber Pakhtunkwhwa Province of Pakististan.

Asare, M. (1997). Married woman and education. Accra Sputnik work.

Baumbusch, Jeniffer L. (2004). Unclaimed treasures: older women's reflection of lifelong singlehood. Journal of women and Ageing. 16, 105-121.

Becker, G. (1981). A treatise on the family. Cambridge, MA: Harvard University Press.

Becker, J. (2000). Women and University education in Africa. Research work sponsored by Kenya Human Rights Syndicate.

Byrne A. and Carr, D. 2005. 'Caught in the Cultural Lag: The Stigma of Singlehood'. Psychological Inquiry: International Journal for the Advancement of Psychological Theory. Vol. 16: 84-91.

Depaulo, B.M (2013). Single in a Society preoccupied with couples. R.J. Coplan, J.C Bowker (Eds). The handbook of solitude: psychological perspectives on social isolation, social withdrawal, and being alone. John willey \& Sons. 302-316.

Dingeman, E and Ingen, EV. (2015). Does religion breed trust? A cross-sectional study of religious involvement, religious faith and religious context on social trust. Journal for the scientific study of religion. 54(4). 739-755.

Fong M.S \& Amatea, E.S (1992). Stress and single professional women. An exploration of causal factors. Journal of Mental Health Counselling. 14 (1), 20-29.

Frustenberg, F.F. (2015). Will marriage disappear? Proceedings of the American Philosophical Society, 158 (3). 241246.

Hallman, K. \& Grant, M. (2004). Poverty, Educational Attainment, and Livelihoods: How Well Do Young People Fare in KwaZulu Natal, South Africa? Horizons Research Summary, Washington,D.C.:Population Council. Retrieved from http://www.popcouncil.org/pdfs/horizons/ythkznsum.pdf Lee.

Hamamura, T. (2012). Are cultures becoming individualistic? A cross-temporal camparism of individualismcollectivism in the United States and Japan. Personality and Psychological Review. 16. 3-24.

Haq, M. (200o). Human Development is South Asia: The Gender Question. Oxford University Press. Karachi Pakistan. p. 105.

Himawan, K. K. (2017). Modernisation and singlehood in Indonesia: psychological and social impacts. https//doi.org/10.1016/j.kjss.2017.09.008.

Jejeebhoy, S. J. (1998). Wife-beating in rural India: a husband's right? Evidence from survey data. Economic and Political Weekly 23(15): 855-862.

Kamau, N. A. (2011). Outsiders within: Experiences of Women Academics in Kenya. In Oyeronke Oyewunmi. (ed). Gendering Epistemologies in Africa; Gendering Traditions, Spaces, Social institution and Identities. Palgrave Macmillan.

Khan, R. and Ali, K. (2005). Bargaining over sons and daughters' schooling: Probit analysis of household behaviour in Pakistan. Working Paper 01-05, Department of Economics, Islamia University, Bahawalpur, Pakistan

Labourne, J. (1996). Closing the gender gap: Women in the accounting profession. Australian Accountant. Vol. 66 Iss. 6.

Latif, A. (2009). A Critical Analysis of School Enrolment and Literacy Rates of Girls and Women in Pakistan. Educational Studies, Vol. 45, Issue 5. Pp. 424- 439

Lee, T. \& Myers, W., (2005). Modern woman student and family problems. McMillan Publishing Company: New York.

Lewis G. \& Moon, S (1997). Always singles and single again women: A qualitative study. Journal of Marital and Family Therapy. 23 (2), 115-134.

Mana Sagy and Srour(2016). Sense of Community coherence and inter-religious relations. Journal of Social Psychology. 56(5) 469-82.

Mawusi, P \& Manieson, E. (2015). Issues and Challenges confronting married women in Tertiary Institutions. International Journal of Education, Learning and Development. Vol.3, No, 9. 19-27.

Ntoimo, F.C. (2012). Prevalence, Determinants and Consequences of Spinsterhood in Lagos, Nigeria. Unpublished PhD thesis in the Department of Sociology Submitted to the Faculty of the Social Sciences in partial fulfilment of the requirements for the Degree of Doctor of Philosophy. 
Onsongo, Jane (2004). Factors affecting Women's Participation in University management in Kenya. Organisation for Social Science Research in Eastern and Southern Africa. Gender Issues Research Report. Series no. 22.

Oyeronke Oyewunmi. (2011). Gendering Epistemologies in Africa; Gendering Traditions, Spaces, Social institution and Identities. Palgrave Macmillan.

Quartey, D., (2003). Married student and traditional role in Ghana. Accra: Mayfield Publishers.

Robertson, C. 1985. A growing dilemma: Women and change in African primary education 1950-1986. In Women and Development in Africa, ed. Gideon Were. Nairobi: Were Press.

Robinson-Pant, A. (2004). Education for women: whose values count? Gender and Education. Vol. 16, No. 4, pp. 473-489.

Rossel, J. 2012. Modernisation. H.K. Anheier, M. Juergensmeyer (Eds). Encyclopaedia of global studies, SAGE. Thousand Oaks. CA (2012) 1178-1182.

Situmorang, A.2007. Staying single in a married world. Asian population studies. 3 (3). 122-126.

Smith, D. J. 2007. Modern marriage, men's extramarital sex, and HIV risk in South eastern Nigeria. American Journal of Public Health, 97(6):997-1005

Still, L.V., (1994). Where to from here? Women in management. Women in Management Review. Vol. 9 No. 4, pp. 3-10

Sweeney, M. M. (2002). Two decades of family change: The shifting economic foundation of marriage. American Sociological Review. 67(1), 132-147.

Tan, J.E .2010. Social relations in the modern age; never-married women in Bangkok, Jakarta, and Manila. Journal of Comparative Family Studies, 41(5), 749-65.

UNDP Report. (1998). Human Development Report. Oxford University Press, New York, NY

Yoshida, 2017. Unmarried women in Japan: The drift into singlehood. Routledge. New York, NY.

Zubaidah, Z, Penafort, F, Jusoff, K, \& Marzuki, M. (2008). Impediments to Women accountant career progression in Malaysia. 